\title{
Congress looks for methods to assess clinical research
}

Washington. Attempts by the US Congress to get the best health care for its money have made it a central, if unwitting, figure in a fierce debate between researchers over methods to assess medical data. And a new congressional report aimed at resolving some of the issues has instead only fanned the flames.

The report*, by the congressional General Accounting Office (GAO), advocates the use of a new method of meta-analysis known as 'cross design synthesis' - to combine the results from clinical trials and medical databases. But by siding with those who would use statistics to make up for deficiencies in existing clinical trials and other biomedical data, the GAO report advocates a methodology that critics describe as shoddy science and statistical legerdemain.

Legislators are looking for ways to quantify therapies that work best and give the best value for money. In the absence of scientific consensus, they have turned to what is known variously as 'technology assessment' or 'outcome assessment'. In 1989, Congress created the Agency for Health Care Policy and Research (AHCPR) within the Department of Health and $\mathrm{Hu}$ man Services to carry out such studies. Its annual funding has risen steadily, and now stands at $\$ 120$ million.

But Congress is doing more than handing over the money. It has also sought to dictate which approaches should be used. On congressional order, the agency is spending more than $\$ 60$ million on studies that combine existing clinical trial results with databases of insurance company or hospital records (known as 'administrative claims data'), or on research into the statistical techniques themselves. By encouraging researchers to combine and reanalyse previously inconclusive clinical trials or to comb through existing computer databases, legislators hope that they can avoid paying for long and expensive clinical trials.

But that is heresy to many researchers. The idea that analysis of computer databases can replace careful clinical trials "is not serious science, it's serious fund raising", says Richard Peto of the University of Oxford.

Most researchers agree that metaanalysis, broadly defined as the statistical analysis and combination of other studies, is a useful and sometimes essential tool. It works best as a way to draw conclusions from randomized clinical trials that are not sufficiently convincing by themselves because of small sample sizes, design flaws or other problems.

But an increasing number of researchers are applying meta-analysis and other related statistical techniques to non-randomized clinical trials, trials with known and unknown biases and even database studies. They believe they can 'adjust' for whatever defects exist in the studies. Several groups are developing computer programs that would automatically correct many of the statistical flaws.

The use of meta-analysis and database analysis is fostered by money from AHCRP. Eminent researchers such as Harvard University's Thomas Chalmers - considered the father of the clinical trial - think metaanalysis is essential to clinical research. Dozens of private groups, from the American Medical Association and the insurance industry to the office of medical applications of research at the US National Institutes of Health (NIH), are now using the two techniques in their own technology or outcome assessments (see Nature 351, 598; 1991).

But several cases have raised questions about the value of using old and flawed data. A 1990 study that compared two treatments of prostate disease - surgery and a relatively new trans-urethral method - found that patients who received the non-surgical treatment had a greater chance of dying within the next few years. But the cause of death, paradoxically, was rarely related to the prostate. A study published earlier this year revealed that, because the trans-urethral method was less physically traumatic, doctors tended to use it on their older and sicker patients; these patients were, of course, also the most likely to die within a few years. When the data were corrected for comorbidity before surgery, the differences in mortality disappeared.

In the case of Herbert Needleman, a researcher at the University of Pittsburgh, a debate over meta-analysis may go to court. His 1990 analysis of 12 studies suggested a clear link between low-level lead consumption and reduced intelligence in children. But two other researchers did their own meta-analysis of many of the same data and found no link. Because the researchers were unable to reconcile their scientific differences, the debate turned into allegations of misconduct and has led to investigations by the university and NIH (see Nature 356, 466, 9 April 1992).

Critics of both outcome and technology assessment say that such cases illustrate the risks of using flawed, incomplete or deceptive data. Researchers such as Salim Yusuf, head of a clinical trials branch in the US National Heart Lung and Blood Institute, and Earl Steinberg, director of the medical technology assessment programme at Johns Hopkins University, say that no amount of manipulation can extract trustworthy results from flawed data. And they are quick to cite a maxim from the computer industry: "Garbage in, garbage out".

Rather than trying to make do with existing data, many researchers want to carry out new and better clinical trials. With backing from the congressional Office of Technology Assessment (OTA) and parts of NIH, these scientists are asking for money for cheap, simple and large trials. One such trial was the International Studies on Infarct Survival that looked at heart disease in more than 30,000 persons from three countries.

The debate has led some members of Congress to reconsider their support for meta-analysis. Later this year, the Senate Labor and Human Resources Committee is expected to ask the OTA, which has traditionally been critical of statistical assessment techniques in medicine, to evaluate the various methods. Meanwhile, the New York Academy of Sciences is planning a conference to discuss the need for large-scale clinical trials. Both sides in the debate agree that their goals are better trials and better statistical evaluation of existing data.

Christopher Anderson

* Cross Design Synthesis: A New Strategy for Medical Effectiveness Research, US General Accounting Office; 1992.

\section{Visitors to China urged to protest}

Researchers travelling to China who want to protest at the imprisonment of Chinese scientists can now do it by the book.

A New York-based human rights group has released a guide to putting pressure on the Chinese government on behalf of researchers who have been jailed for political activism. In the guide, the Committee to End the Chinese Gulag suggests ways to help some 65 scientists now confined.

One approach, it says, is to present conference organizers with a list of imprisoned researchers. Dedicating a paper to such a researcher or collecting signatures on a petition are other options, as is displaying a protest poster. Scientists can also request an appointment with government officials, although the chances of success are slim. The guide (which may be obtained by calling 212-972-8400) also describes how to obtain publicity for any protests, especially if they are disrupted by Chinese authorities.

China is hosting a growing number of scientific conferences in an attempt to improve its international image, including major meetings this year on the physics of semiconductors and on entomology. Some physicists are boycotting the meeting in protest. For those who attend, the guide advises caution. Last week, China detained and expelled seven European legislators and union leaders after they staged a brief protest in Tiannanmen Square.

Christopher Anderson 